\title{
Effects of operating parameters on hydrogen production from raw wet steam-exploded cornstalk and two-stage fermentation potential for biohythane production
}

\author{
Zhidan Liu ${ }^{\mathrm{a}, \#}$, Qian Lic ${ }^{\mathrm{c}}$, , Chong Zhang ${ }^{\mathrm{b}}$, Linjun Wang ${ }^{\mathrm{b}}$, Bing Han ${ }^{\mathrm{d}}$, Baoming $\mathrm{Li}^{\mathrm{a}}$, \\ Yuanhui Zhang ${ }^{\mathrm{e}}$, Hongzhang Chen ${ }^{\mathrm{f}}$, Xin-Hui Xing ${ }^{\mathrm{b}}$ *
}

${ }^{a}$ Lab. of Environment-Enhancing Energy (E2E), College of Water Resources and Civil Engineering, China Agricultural University, Beijing, 100083, China;

${ }^{\mathrm{b}}$ Department of Chemical Engineering, Tsinghua University, Beijing 100084, China;

${ }^{c}$ Department of Environmental Engineering, University of Science and Technology Beijing, Beijing 100083, China;

${ }^{\mathrm{d} C h i n a}$ 's National Institute for Clean-and-Low-Carbon Energy (NICE), Beijing 102209, China;

${ }^{e}$ Department of Agricultural and Biological Engineering, University of Illinois at Urbana-Champaign, Urbana, IL 61801, U.S.A.;

${ }^{\mathrm{f}}$ National Key Laboratory of Biochemical Engineering, Institute of Process Engineering, Chinese Academy of Sciences, Beijing 100190, China

*Corresponding author: Prof. Xin-Hui Xing

Tel: +86-10-6279-4771; Fax: +86-10-62787472; Email: xhxing@ tsinghua.edu.cn

\# These authors contributed equally to this work. 


\begin{abstract}
Biohythane (biohydrogen+biomethane) production from agricultural residue is a win-win solution for the supply of renewable energy and valorization of waste biomass. This study reported the first investigation on hydrogen fermentation directly using raw wet steam-exploded cornstalk (SC) without any further processing for drying or detoxification. The effects of key operating parameters (feedstock concentration, initial $\mathrm{pH}$ and heat treatment of seed sludge) were systematically studied. The suitable conditions for hydrogen fermentation from the wet SC were the feedstock concentration at $200 \mathrm{~g} \mathrm{~L}^{-1}$ (TS, 6 8\%), $\mathrm{pH}$ at 6.5 and seed sludge without heat treatment. In addition, compared to one-stage biomethane fermentation, the two-stage biohythane fermentation by integrating hydrogen fermentation with biomethane production from SC led to the hydrogen and methane yields of 12 and $195 \mathrm{~L} \mathrm{~kg}^{-1} \mathrm{TS}^{-1}$, respectively, corresponding to an increased energy recovery of $26 \%$, reduced fermentation time and facilitated conversion of volatile fatty acids. These results demonstrated the feasible energy-efficient biohydrogen or biohythane production from the wet steam-exploded cornstalk, implying the promising potential of this method for harvesting clean hythane vehicle fuel from agricultural biomass.
\end{abstract}

Keywords: Anaerobic processes, Biohydrogen, Bioconversion, Biogas, Fermentation, Steam-exploded cornstalk

\title{
1. Introduction
}

The energy crisis is becoming a global issue. Hydrogen, as a clean and efficient renewable energy, is considered to be the best alternative to fossil fuels [1-4]. However, commercialization of hydrogen energy is hampered by a cost-intensive process. Hythane, a mixture of hydrogen and methane, has attracted significant attention as a transit form of pure hydrogen in the near term [5]. With the addition of hydrogen to methane, hythane has been noted to exhibit obvious advantages over compressed natural gas as a vehicle fuel, such as extended flammability range, shortened quenching distance, reduced greenhouse gas emissions, and improved fuel 
efficiency [6]. Hythane could be sustainably produced from biomass through microbial fermentation (biohythane) [7,8]. With the development of agriculture, the yield of agricultural residues has increased up to about 700 million tons a year in China [9]. Therefore, utilization of agricultural residues for the production of biohythane through two-stage anaerobic fermentation is an important way to valorize the agricultural waste, reduce environmental pollution, and, to some extent, complement the constrained energy supply.

Lignocellulosic agricultural biomass, such as cornstalk, has natural recalcitrance with a highly rigid three-dimensional structure mainly consisting of cellulose, hemicellulose, and lignin, making it very difficult to degrade and transform [10]. Steam explosion has already been recognized as an efficient approach to breaking up the structure of lignocelluloses, where the changes in the water forms serve as the main factor [11, 12]. However, the hydrolysate obtained after steam explosion contains many fermentation inhibitors, including phenolic compounds, furfural, acetic acid, etc. [13]. An additional step of detoxification is generally needed to remove these inhibitors, including the use of milk of lime [14], organic solvent extraction [15], activated carbon adsorption [16], concentration under vacuum [17], and ion exchange [18]. Moreover, steam-exploded cornstalk (SC) always needs to be dried before the use in the subsequent bioprocess, thus making the whole process energy-intensive, water-unsustainable, and industrially undesirable. It is therefore of crucial importance to study the possibility of directly utilizing wet SC in anaerobic fermentation. However, so far there is no report on the effects of the wet steam-exploded cornstalk on anaerobic fermentation for the production of either biohydrogen, biomethane or biohythane.

The purposes of the current study were to 1) investigate the feasibility of hydrogen fermentation directly using wet SC without detoxification and drying; 2) evaluate the influence of process parameters (feedstock concentration, initial $\mathrm{pH}$ and heat treatment of seed sludge) on hydrogen fermentation by using a normal-pressure batch bioreactor; and 3) examine the biohythane production potential from wet SC by using two-stage anaerobic fermentation. 


\section{Materials and methods}

\subsection{Seed sludge, substrate and medium}

The anaerobic sludge, sampled from an anaerobic digester of Xiaohongmen Wastewater Treatment Plant (Beijing, China), was used as the seed sludge. Three different SC were used as substrates: a dried one (TS, >90\%; VS/TS, 84-86\%) taken from a factory in Shandong (abbr. SDSC); a wet one (TS, 28-30\%; VS/TS, 76-80\%) directly taken from Laihe Company (abbr. LHSC). The concentrations of HMF and FUR in LHSC were in ranges of 90 150 and 60 165 mg/L, respectively; and another dried one (TS, >90\%; VS/TS, 90-96\%) taken from Prof. Chen Hongzhang's laboratory (Institute of Process Engineering, Chinese Academy of Sciences) (abbr. LASC). The medium contained the following $\left(\mathrm{L}^{-1}\right)$ : yeast extract, $2.0 \mathrm{~g}$; $\left(\mathrm{NH}_{4}\right)_{2} \mathrm{SO}_{4}$, $1.3 \mathrm{~g} ; \mathrm{KH}_{2} \mathrm{PO}_{4}, 1.5 \mathrm{~g} ; \mathrm{K}_{2} \mathrm{HPO}_{4} \cdot 3 \mathrm{H}_{2} \mathrm{O}, 2.9 \mathrm{~g} ; \mathrm{CaCl}_{2}, 0.075 \mathrm{~g} ; \mathrm{MgCl}_{2} \cdot 6 \mathrm{H}_{2} \mathrm{O}, 0.2 \mathrm{~g}$; and $\mathrm{FeSO}_{4} \cdot 7 \mathrm{H}_{2} \mathrm{O}, 1.25 \mathrm{mg}$. The $\mathrm{pH}$ of all the substrates was $6 \sim 6.5$ unless otherwise stated.

\subsection{Experimental system and procedure}

The experiment device was a normal-pressure bioreactor system, consisting of 250-ml glass flask with a working volume of $150 \mathrm{ml}$, gas-tight plastic tubes, sampling valve, and gas balloon. The glass flask served as the anaerobic vessel for fermentation, the produced gas was measured using the gas sampling valve and collected by gas balloon, and the fermented broth was sampled by the sampling port embedded in the flask. The feasibility study of hydrogen fermentation from the wet SC was first investigated by examining the effects of key operating parameters, including SC types and concentration, initial $\mathrm{pH}$ and heat pretreatment of seed sludge. The flask bioreactors containing substrate were degassed with pure nitrogen for 30 min to reach anaerobic conditions prior to use. To determine the influence of substrate concentration, 40,100, 200, 400, and $800 \mathrm{~g} \mathrm{~L}^{-1}$ of substrate were tested, respectively. To evaluate the effect of $\mathrm{pH}$ on anaerobic fermentation, the medium with initial $\mathrm{pH}$ of 5.5, 6.5, and 7.5 were prepared. With regard to detection of the effect of heat pretreatment of seed sludge, the experiments were performed using a water bath with 
temperatures controlled at 50,80 , and $100^{\circ} \mathrm{C}$, respectively. $7 \%(\mathrm{w} / \mathrm{v})$ of the boiled anaerobic sludge $(70 \mathrm{~g} / \mathrm{L})$ was inoculated in a flask culture for biohydrogen production [19].

The biochemical potential for coproduction of hydrogen and methane (biohythane) [7] from SC was then investigated under the optimized conditions compared to one-stage biomethane process. The one-stage biomethane experiment was carried out using an initial $\mathrm{pH}$ of 7.5 , whereas the two-stage fermentation for biohythane production was performed using an initial $\mathrm{pH}$ of 6.5 for hydrogen fermentation, followed by adjusting $\mathrm{pH}$ to 7.5 for the subsequent methane fermentation when hydrogen production was ceased in the same flask culture system.

\subsection{Analytical methods}

Gas samples were analyzed by using a gas chromatograph equipped with a thermal conductivity detector (TCD) and a column packed with TDX-01 (GC112A, China) [20]. The detected gases included hydrogen, oxygen, and methane. Metabolic intermediates during microbial fermentation were analyzed by a high performance liquid chromatography (HPLC; Shimadzu 10A) equipped with a refractive index detector (RID) and a Shodex RSpak KC-811 column. $\mathrm{HClO}_{4}\left(1 \mathrm{~g} \mathrm{~L}^{-1}\right)$ was used as the

mobile phase at a flow rate of $1 \mathrm{ml} \mathrm{min}^{-1}$. The samples were centrifuged $(12,000 \mathrm{rpm}$, $10 \mathrm{~min}$ ) and the supernatant was filtered using a $0.22-\mathrm{mm}$ membrane filter before use. The detected intermediates included volatile fatty acids (VFAs) and ethanol.

The concentrations of soluble sugars were measured by employing the phenol-sulfuric acid method [21]. Cellulose, hemicelluloses, and lignin in the pretreated and fermented cornstalks were evaluated according to the procedures reported by National Renewable Energy Laboratory (NREL) [22].

The utilized glucose equivalent was calculated based on carbon balance during microbial fermentation, and its detailed description has been given elsewhere [19]. Energy recovery was calculated by dividing the combustion values of hydrogen and methane produced by that of cornstalk [19]. The combustion values of hydrogen, methane, and glucose are 280,864 , and $2870 \mathrm{~kJ} \mathrm{~mol}^{-1}$, respectively, and a detailed 
description has been given elsewhere [19].

\section{Results and discussion}

\subsection{Hydrogen fermentation using SC}

\subsubsection{Effects of SC types and concentrations on hydrogen fermentation}

Table 1 shows the comparison of hydrogen productivity using different SC as feedstocks. LHSC achieved a maximum hydrogen yield of $10.21 \mathrm{~L} \mathrm{~kg}^{-1} \mathrm{TS}^{-1}$. Compared with the dried SC, such as SDSC and LASC, LHSC contained more soluble sugar and VFAs, which contributed to more hydrogen production.

The effect of feedstock concentrations on hydrogen fermentation was then studied using LHSC. With the increase in the substrate concentration from 40 to $200 \mathrm{~g}$ $\mathrm{L}^{-1}$, the hydrogen yield increased up to $10.41 \mathrm{~L} \cdot \mathrm{kg}^{-1} \mathrm{TS}^{-1}$. However, the hydrogen production ceased when the substrate concentration was $400 \mathrm{~g} \mathrm{~L}^{-1}$ and $800 \mathrm{~g} \mathrm{~L}^{-1}$. A similar phenomenon was observed through the analysis of metabolites after fermentation. When the substrate concentration was increased up to $200 \mathrm{~g} \mathrm{~L}^{-1}$, acetic acid reached its maximum $(5.54 \mathrm{mM})$, whereas decreased VFAs were observed when the substrate concentration reached $400 \mathrm{~g} \mathrm{~L}^{-1}$. Substrate concentration is an important factor for anaerobic fermentation. The current results demonstrated that $200 \mathrm{~g} \mathrm{~L}^{-1}$ was a suitable concentration for hydrogen fermentation. The substrate at high concentration (400 or $800 \mathrm{~g} \mathrm{~L}^{-1}$ ) might result in uneven mass transfer and contain a high amount of fermentation inhibitors, thereby suppressing hydrogen fermentation according to the study by Chen et al.[13].

\subsubsection{Effect of initial $\mathrm{pH}$ on hydrogen fermentation}

At an initial $\mathrm{pH}$ of 6.5 , the hydrogen yield exhibited significant changes from 0 to $86 \mathrm{~h}$ (Fig. 1A). At $86 \mathrm{~h}$, the hydrogen yield approximately reached the maximum value of $3.76 \mathrm{~L} \mathrm{~kg}^{-1} \mathrm{TS}^{-1}$. The hydrogen yield didn't change much after $86 \mathrm{~h}$. Unlike the value at $\mathrm{pH} 6.5$, the maximum hydrogen yields at $\mathrm{pH} 7.5$ and 5.5 were only 1.37 and $0.14 \mathrm{~L} \mathrm{~kg}^{-1} \mathrm{TS}^{-1}$, respectively. The hydrogen content reached its maximum of $26 \%$ at $\mathrm{pH} 6.5$ and $37 \mathrm{~h}$. Obviously, the initial $\mathrm{pH}$ of 6.5 was suitable for hydrogen 
fermentation, because hydrogen fermentation is generally carried out under acidic conditions, especially when anaerobic sludge is used as inoculum. Acidic condition may suppress methane production. Zhang et al. [23] reported that NADH generated in the EMP pathway also regulated hydrogen production through the balance of $\mathrm{NAD}^{+} / \mathrm{NADH}$ under acidic conditions. A higher initial $\mathrm{pH}$ of more than 7.0 may stimulate biomethane process, thus decreasing hydrogen productivity. The optimal $\mathrm{pH}$ was suggested in a wide range of 4.0 7.0 depending on many factors, such as inoculums and substrates [3]. Moreover, analysis of the fermented liquid products (Fig. 1B) revealed that lactic acid was induced at $\mathrm{pH}$ 5.5, whereas more acetic acid and propionic acid were produced at $\mathrm{pH}$ 7.5. These results implied that control of $\mathrm{pH}$ is of importance to hydrogen fermentation from the wet steam-explored in terms of both hydrogen productivity and VFA composition, since more acetic acid would be desirable for the subsequent methane fermentation.

\subsubsection{Effects of seed sludge heat treatment on hydrogen fermentation}

Figure 2 shows the effect of heat treatment $\left(0,50,80\right.$, and $\left.100^{\circ} \mathrm{C}\right)$ of seed sludge on hydrogen fermentation. Interestingly, the hydrogen yields using the seed sludge without treatment and after heat treatment at $100^{\circ} \mathrm{C}$ were similar, at around $9 \mathrm{~L} \mathrm{~kg}^{-1}$ $\mathrm{TS}^{-1}$, higher than those achieved at 50 and $80^{\circ} \mathrm{C}$. The analysis of metabolites after fermentation (Fig. 2B) showed that higher heating temperature resulted in increased production of propionic acid and formic acid, compared with the control. Heat treatment at $100^{\circ} \mathrm{C}$ is generally regarded as an efficient method to inactivate the hydrogenotrophic bacteria and enrich hydrogen-producing spore-forming bacteria, such as Clostridium sp [3, 24]. In comparison, these results revealed that heat treatment of seed sludge had little influence on hydrogen fermentation from the wet SC. A possible reason was the complexity of the wet SC containing fermentation inhibitors, which might selectively favor hydrogen fermentation according to $\mathrm{Li}$ et al [11]. We recently found that fermentation inhibitors, specifically furfural and 5-hydroxymethyl furfural, were degraded through hydrogen fermentation and even enhanced the biohydrogen production [25]. However, further study on the mechanism 
needs to be carried out.

3.2 Potential for biohythane production from wet SC by two-stage hydrogen and methane fermentation

Based on the optimized conditions for hydrogen fermentation directly from the raw wet SC, the potential for coproduction of hydrogen and methane (biohythane) via hydrogen fermentation followed by methane fermentation was evaluated by using a self-developed normal-pressure bioreactor system. Anaerobic sludge of $70 \mathrm{~g} \mathrm{~L}^{-1}$ (7\%, w/v) was used as the inoculum and $200 \mathrm{~g} \mathrm{~L}^{-1}$ of LHSC was used as the feedstock. Compared with the one-stage methane process, the two-stage biohythane process significantly enhanced hydrogen production by $49 \%$ and methane production by $25 \%$ (Fig. 3). This corresponded to a $26 \%$ increase in the total energy recovery. Under the conditions for biohythane production, a hydrogen yield of $12 \mathrm{~L} \mathrm{~kg}^{-1} \mathrm{TS}^{-1}$ and a methane yield of $195 \mathrm{~L} \mathrm{~kg}^{-1} \mathrm{TS}^{-1}$ were achieved, corresponding to an energy recovery of more than $100 \%$. This might be due to the fact that the coproduction of biohydrogen and biomethane from biomass is an endothermic reaction, with a theoretical energy recovery of more than $100 \%$ [7]. In addition, as shown in Fig.3, to obtain the same energy recovery, the required time for the two-stage biohythane process was much shorter than that for the single-stage methane process. Analysis of fermentation metabolites (Table 2) showed that all the VFAs were converted into gas biofuels after 60 days' operation. One interesting finding was that one-stage biomethane fermentation generated much higher propionic acid $(11 \sim 12 \mathrm{mM})$ at $22 \mathrm{~d}$ and $30 \mathrm{~d}$ than the two-stage biohythane process, suggesting that more efficient conversion of propionic acid into acetic acid was achieved in the biohythane process. Chu et al.[26] reported similar results using food waste as the substrate for the coproduction of biohydrogen and biomethane. Compared to easily biodegradable food waste, cornstalk has the cellulosic recalcitrance with a highly rigid three-dimensional structure, making it very difficult to degrade and convert. Cornstalk was hydrolyzed and liquefied through microorganism [19] or alkali chemicals [27] before its utilization for the coproduction of biohydrogen and biomethane. However, the direct 
conversion of wet SC containing liquid and solid organics into biohythane has not been reported elsewhere. Table 3 indicated that hydrolysis of cornstalk were not significantly affected by the fermentation stages. Cellulose and hemicellulose were completely degraded and the total hydrolysis rates were around 50-60\% after fermentation under both conditions.

The direct use of the raw wet SC for biohydrogen and biohythane production as shown in this study was a useful approach for biorefinery of agricultural biomass. Most study using SC for fermentation had to undergo energy-intensive drying or extra detoxification before fermentation [13]. Compared with the fermentation using dried or detoxified SC (TS $>90 \%$ ) as substrate, almost $60 \%$ of water could be saved by directly using wet steam-exploded cornstalk (TS, 28-30\%), thus making the process more feasible. Furthermore, $\mathrm{pH}$ of the wet $\mathrm{SC}$ was $6-6.5$, which is particularly suitable for hydrogen fermentation, thus saving the operating cost for $\mathrm{pH}$ adjustment. However, the sustainability of the biohythane process needs to be considered. This study is focused on the potential of biohytane generation from wet SC. Further work is needed to investigate the biohythane production in continuous operation and evaluate its process economy, which is ongoing now.

\section{Conclusions}

The current study demonstrated that raw wet SC could be directly used for hydrogen fermentation without any further step for detoxification or drying. The analysis of gas production and metabolites indicated that initial $\mathrm{pH}$ and feedstock concentration greatly impacted hydrogen productivity, whereas heat treatment was found unnecessary for hydrogen production from the wet SC. A maximum hydrogen yield (10 $\left.\mathrm{L} \mathrm{kg}^{-1} \mathrm{TS}^{-1}\right)$ and hydrogen content (36.83\%) were achieved under the optimized conditions at $200 \mathrm{~g} \mathrm{~L}^{-1}$ of substrate, initial $\mathrm{pH}$ of 6.5 and seed sludge without heat treatment. Furthermore, the two-stage biohythane process led to a maximum hydrogen yield of $12 \mathrm{~L} \mathrm{~kg}^{-1} \mathrm{TS}^{-1}$ and methane yield of $195 \mathrm{~L} \mathrm{~kg}^{-1} \mathrm{TS}^{-1}$, $26 \%$ higher in the total energy recovery than one-stage biomethane fermentation with reduced fermentation time, indicating the potential of this method for harvesting clean 
hythane vehicle fuel from waste biomass.

\section{Acknowledgments}

This work was supported by NSFC project (21106080), NSFC-JST Cooperative Research Project (21161140328), the Project of the National Basic Research Program of China (973 Plan) (2011CB707404), and Chinese Universities Scientific Fund (2012RC030).

\section{References}

1. YHP. Zhang, Renewable carbohydrates are a potential high-density hydrogen carrier, Int. J. Hydrogen Energy. 35(2010) 10334-10342.

2. N. Ren, A. Wang, G. Cao, J. Xu, L. Gao, Bioconversion of lignocellulosic biomass to hydrogen: Potential and challenges, Biotechnol. Adv. 27(2009) 1051-1060.

3. J. Wang, W. Wan, Factors influencing fermentative hydrogen production: a review, Int. J. Hydrogen Energy. 34(2009) 799-811.

4. H. Zheng, C. Zhang, Y. Lu, P.X. Jiang, X.H. Xing, Alteration of anaerobic metabolism in Escherichia coli for enhanced hydrogen production by heterologous expression of hydrogenase genes originating from Synechocystis sp., Biochem. Eng. J. 60(2012) 81-86.

5. J. Fulton, R. Marmaro, G. Egan, F. Lynch, System for blending and compressing gases. US patent 77400312010.

6. C.G. Bauer, T.W. Forest, Effect of hydrogen addition on the performance of methane-fueled vehicles. Part I: effect on S.I. engine performance, Int. J. Hydrogen Energy. 26(2001) 55-70.

7. Z. Liu, C. Zhang, Y. Lu, X. Wu, L. Wang, L. Wang, B. Han, X.H. Xing, States and challenges for high-value biohythane production from waste biomass by dark fermentation technology, Bioresour. Technol. 135(2013) 292-303.

8. M. Ljunggren, G. Zacchi, Techno-economic analysis of a two-step biological 
process producing hydrogen and methane, Bioresour. Technol. 101(2010)7780-7788.

9. T. Tan, F. Shang, X. Zhang, Current development of biorefinery in China, Biotechnol. Adv. 28(2010):543-555.

10. D.B. Levin, C.R. Carere, N. Cicek, R. Sparling, Challenges for biohydrogen production via direct lignocellulose fermentation, Int. J. Hydrogen Energy. 34(2009)7390-7403.

11. D. Li, H. Chen, Biological hydrogen production from steam-exploded straw by simultaneous saccharification and fermentation, Int. J. Hydrogen Energy.32 (2007) $1742-1748$.

12. H. Chen, G. Li, An industrial level system with nonisothermal simultaneous solid state saccharification, fermentation and separation for ethanol production, Biochem. Engi. J. 74 (2013)121-126.

13. H. Li, H. Chen, Detoxification of steam-exploded corn straw produced by an industrial-scale reactor, Process Biochem. 43(2008)1447-1451.

14. F.R. Frazer, T.A. Mc Caskey, Wood hydrolyzate treatments for improved fermentation of wood sugars to 2,3-butanedio, Biomass. 18(1989)31-42.

15. J.C. Parajo, H. Dominguez, J.M. Dominguez, Xylitol production from eucalyptus wood hydrolysates extracted with organic solvents, Process Biochem. 32(1997)599-604.

16. J.C. Parajo, H.Dominguez, J.M. Dominguez, Charcoal adsorption of wood hydrolysates for improving their fermentability: influence of the operational conditions, Bioresour. Technol. 57(1996)179-185.

17. J.J. Wilson, L. Deschatelets, N. Nishikawa, Comparative fermentability of enzymatic and acid hydrolysates of steam-pretreated aspenwood hemicelluloses by Pichia stipitis CBS 5776, Appl. Microbiol. Biotechnol. 31(1989)592-596.

18. C. van Zyl, B.A. Prior, J.C. du Preez, Acetic acid inhibition of D-xylose fermentation by Pichia stipitis, Enzyme Microb. Technol. 13(1991) 82-86.

19. Lu Y, Lai Q, Zhang C, Zhao H, Ma K, Zhao X, Chen H, Liu D, Xing X-H: Characteristics of hydrogen and methane production from cornstalks by an $11 / 19$ 
augmented two- or three-stage anaerobic fermentation process. Bioresour. Technol. 100(2009):2889-2895.

20. Z. Liu, F. Lv, H. Zheng, C. Zhang, F. Wei, X.H. Xing, Enhanced hydrogen production in a UASB reactor by retaining microbial consortium onto carbon nanotubes (CNTs), Int. J. Hydrogen Energy. 37(2012) 10619-10626.

21. M. Dubois, K.A. Gilles, J.K. Hamilton, P.A. Rebers, F.L. Smith, Colorimetric method for determination of sugars and related substances, Anal. Chem. 28(1956) $350-356$.

22. A. Sluiter, B. Hames, R. Ruiz, C. Scarlata, J. Sluiter, D. Templeton, D. Crocker. Determination of Structural Carbohydrates and Lignin in Biomass. Laboratory Analytical Procedure (LAP). Technical Report. NREL/TP-510-42618. (2008)

23. C. Zhang, F.X. Lv, X.H. Xing, 2011. Bioengineering of the Enterobacter aerogenes strain for biohydrogen production, Bioresour. Technol. 102(2011) 8344-8349.

24. S. Lakhveer, F.S. Muhammad, A. Anwar, H.R. Mohd, S. Mimi, A.W. Zularisam, Application of polyethylene glycol immobilized Clostridium sp. LS2 for continuous hydrogen production from palm oil mill effluent in upflow anaerobic sludge blanket reactor, Biochem. Engi.J. 70 (2013)158-165.

25. Liu Z ZC, Wang L, He JW, Li B, Zhang Y, Xing X-H: Anaerobic degradation of furan derivatives and their effects on biohydrogen fermentation from wet steam-exploded cornstalk. Biotechnology Biofuels. In revision.

26. Chu C-F, Li Y-Y, Xu K-Q, Ebie Y, Inamori Y, Kong H-N: A pH- and temperature-phased two-stage process for hydrogen and methane production from food waste. Int J Hydrogen Energy, 2008. 33(18):4739-4746.

27. Cheng XY,Liu CZ: Enhanced coproduction of hydrogen and methane from cornstalks by a three-stage anaerobic fermentation process integrated with alkaline hydrolysis. Bioresour. Technol. 104 (2012):373-379. 


\section{Figure captions}

Fig.1 Effect of initial pH on hydrogen fermentation from LHSC (n=3). A, hydrogen yields; B, analysis of metabolites (mM) after fermentation.

Fig.2 Effect of pretreatment temperatures for the seed sludge on hydrogen fermentation from LHSC $(\mathrm{n}=3)$. A, hydrogen yields; B, analysis of metabolites $(\mathrm{mM})$ after fermentation.

Fig.3 Comparison of gas biofuels production from wet LHSC through one-stage biomethane process and two-stage biohythane process $(\mathrm{n}=3)$. A, hydrogen production; $\mathrm{B}$, methane production. 
Table 1 Comparison of hydrogen productivity with different SC ( $\mathrm{n}=3)$. SDSC, dried SC from a factory in Shandong; LASC, dried SC from Prof Chen's laboratory (IPE); LHSC, wet SC directly taken from Laihe Company.

\begin{tabular}{|c|c|c|c|c|c|c|}
\hline $\begin{array}{l}\text { Feed } \\
\text { stock }\end{array}$ & $\begin{array}{l}\text { Concentration } \\
\left(\mathrm{g} \mathrm{L}^{-1}\right)\end{array}$ & $\begin{array}{l}\mathrm{TS} \\
(\%) \\
\end{array}$ & $\begin{array}{l}\text { Volumic } \mathrm{H}_{2} \text { production } \\
\left(\mathrm{L} \mathrm{L}^{-1}\right)\end{array}$ & $\begin{array}{l}\text { Gas } \\
\left(\mathrm{L} \mathrm{kg}^{-1} \mathrm{TS}^{-1}\right)\end{array}$ & $\begin{array}{l}\mathrm{H}_{2} \text { productivity } \\
\left(\mathrm{L} \mathrm{kg}^{-1} \mathrm{TS}^{-1}\right)\end{array}$ & final $\mathrm{pH}$ \\
\hline SDSC & 20 & 1.8 & $0.001 \pm 0.001$ & $12.04 \pm 5.37$ & $0.072 \pm 0.061$ & 6.12 \\
\hline LASC & 20 & 1.9 & $0.02 \pm 0.007$ & $28.95 \pm 3.68$ & $1.01 \pm 0.35$ & $5.58 \pm 0.12$ \\
\hline LHSC & 100 & 4 & $0.28 \pm 0.001$ & 41.23 & $10.21 \pm 0.03$ & $5.15 \pm 0.01$ \\
\hline
\end{tabular}


Table 2 Analysis of fermentation metabolites $(\mathrm{mM})$ during biochemical potential study of LHSC $(n=3)$

\begin{tabular}{llllllll}
\hline Time(d) & Process & Lactic acid & Formic acid & Acetic acid & Propionic acid & n-Butyric acid & Valeric acid \\
\hline \multirow{2}{*}{22} & $\mathrm{O}$ & 0 & 0 & 0 & 0 & 0 & 0 \\
& $\mathrm{~T}$ & 0 & $1.14 \pm 0.45$ & $1.95 \pm 1.13$ & $0.20 \pm 0.28$ & $4.27 \pm 0.64$ & 0 \\
30 & $\mathrm{O}$ & $0.71 \pm 1.00$ & 0 & $1.27 \pm 0.90$ & $12.95 \pm 0.33$ & 0 & 0 \\
& $\mathrm{~T}$ & 0 & 0 & $1.39 \pm 0.55$ & $6.19 \pm 7.83$ & $0.18 \pm 0.25$ & $0.30 \pm 0.42$ \\
38 & $\mathrm{O}$ & 0 & 0 & $0.97 \pm 0.18$ & $11.56 \pm 1.26$ & 0 & 0 \\
& $\mathrm{~T}$ & 0 & 0 & $1.45 \pm 0.07$ & 0 & 0 & 0 \\
45 & $\mathrm{O}$ & 0 & 0 & $1.35 \pm 0.51$ & $3.03 \pm 1.33$ & 0 & 0 \\
& $\mathrm{~T}$ & 0 & 0 & $0.89 \pm 0.27$ & $0.20 \pm 0.28$ & 0 & $0.16 \pm 0.23$ \\
60 & $\mathrm{O}$ & 0 & 0 & 0 & 0 & 0 & 0 \\
& $\mathrm{~T}$ & 0 & 0 & 0 & 0 & 0 & 0 \\
\hline
\end{tabular}

O, One-stage biomethane process (initial $\mathrm{pH} 7.5$ ); T, Two-stage biohythane process (initial $\mathrm{pH} 6.5$ and $\mathrm{pH}$ was adjusted to 7.5 after the hydrogen production). 
Table 3 Analysis of biomass components after anaerobic fermentation of using LHSC.

\begin{tabular}{lllllll}
\hline Process & $\begin{array}{l}\text { Cellulose } \\
\left(\mathbf{g ~ g}^{-\mathbf{1}}\right)\end{array}$ & $\begin{array}{l}\text { Hemicellulose } \\
\left.\mathbf{g}^{-\mathbf{1}}\right)\end{array}$ & $\begin{array}{l}\text { (g Lignin } \\
\left(\mathbf{g ~ g ~}^{-\mathbf{1}}\right)\end{array}$ & $\begin{array}{l}\text { Ash } \\
\left(\mathbf{g ~ g ~}^{-\mathbf{1}}\right)\end{array}$ & $\begin{array}{c}\text { Hydrolysis rate of } \\
\text { SE cornstalk (\%) }\end{array}$ & $\begin{array}{l}\text { Hydrolysis rate of } \\
\text { cornstalk (\%) }\end{array}$ \\
\hline O & n.d. & n.d. & 0.25 & 0.37 & 45.09 & 56 \\
$\mathrm{~T}$ & n.d. & n.d. & 0.18 & 0.32 & 47.97 & 58 \\
\hline
\end{tabular}

$\mathrm{O}$, One-stage biomethane process (initial $\mathrm{pH} 7.5$ ); T, Two-stage biohythane process (initial $\mathrm{pH} 6.5$ and $\mathrm{pH}$ was adjusted to 7.5 after the hydrogen production); n.d., not detectable. 
Fig.1 Effect of initial $\mathrm{pH}$ on hydrogen fermentation from LHSC ( $\mathrm{n}=3)$. A, hydrogen yields; $\mathrm{B}$, analysis of metabolites $(\mathrm{mM})$ after fermentation.
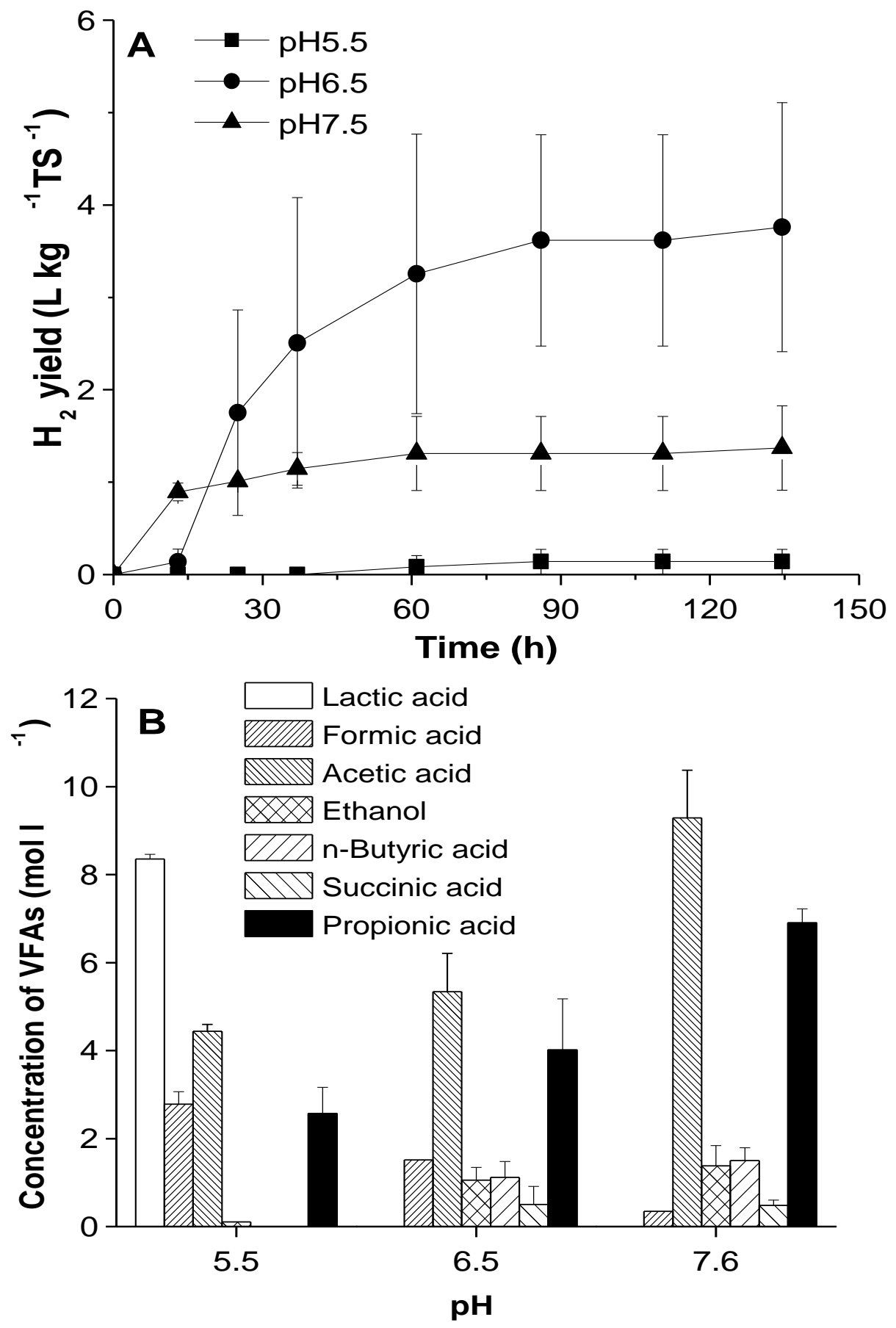
Fig.2 Effect of pretreatment temperatures for the seed sludge on hydrogen fermentation from LHSC $(n=3)$. A, hydrogen yields; B, analysis of metabolites $(\mathrm{mM})$ after fermentation.
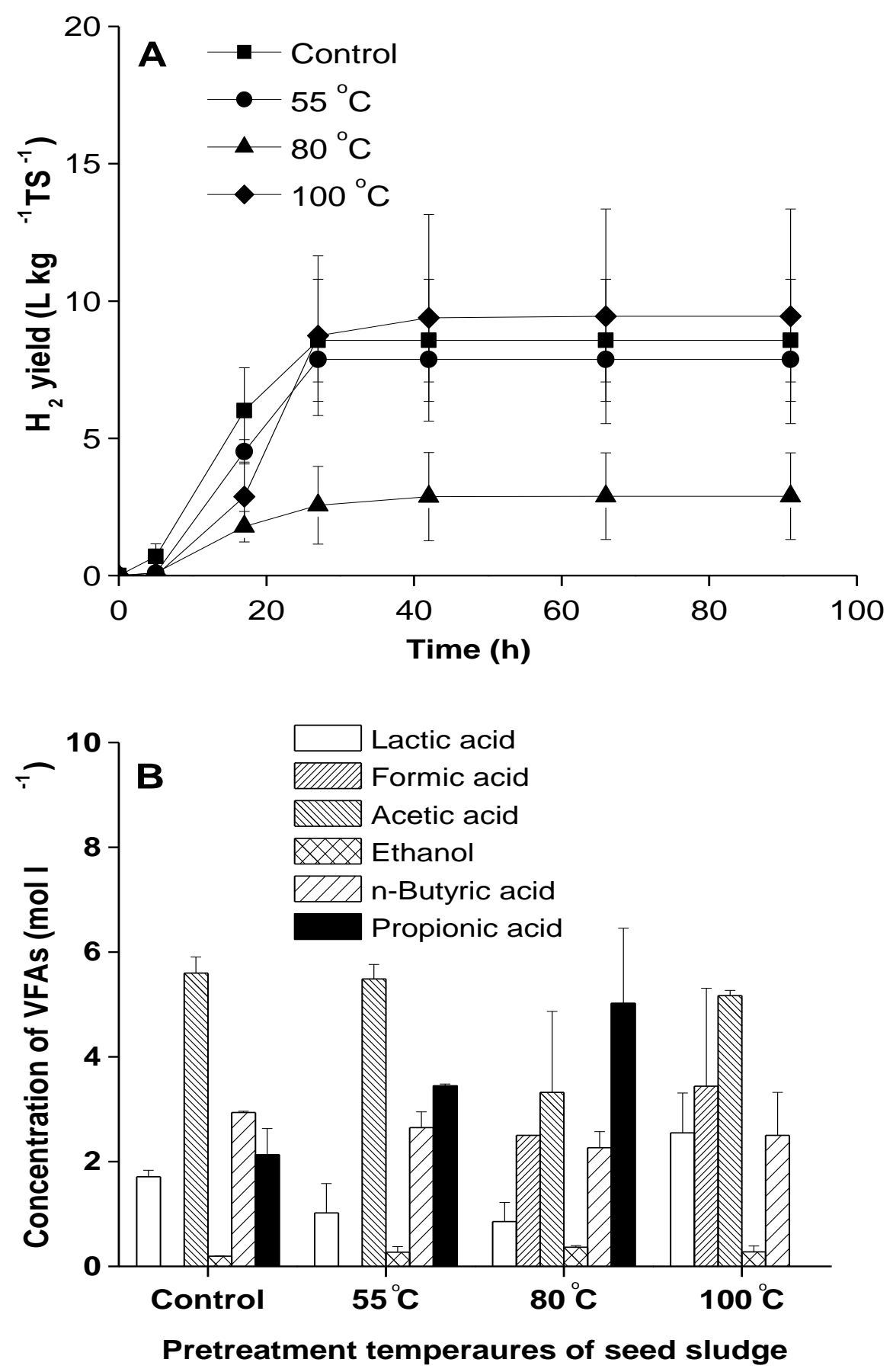
Fig.3 Comparison of gas biofuels production from wet LHSC through one-stage biomethane process and two-stage biohythane process $(n=3)$. A, hydrogen production; $\mathrm{B}$, methane production.

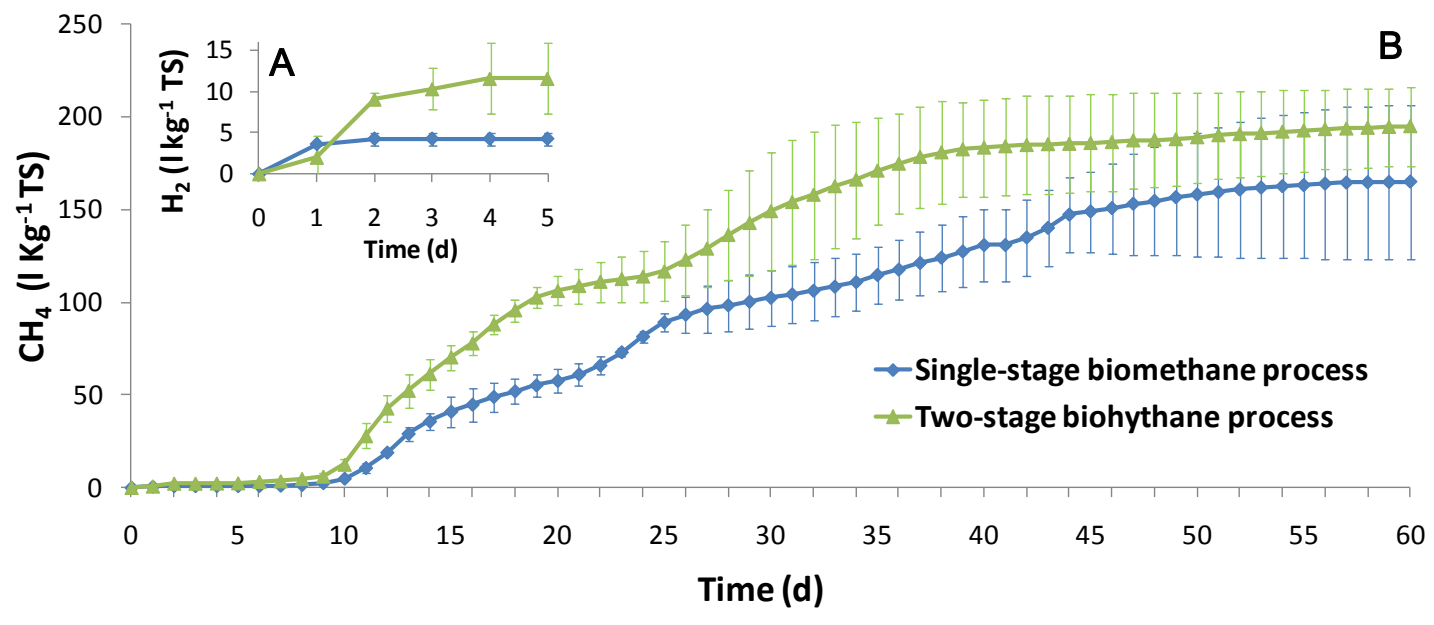

